\title{
AVANÇOS E DESAFIOS NO PROCESSO DE IMPLEMENTAÇÃO DO PROGRAMA NACIONAL DE ALIMENTAÇÃO ESCOLAR (PNAE) E O PROGRAMA DINHEIRO DIRETO NA ESCOLA (PDDE)
}

\author{
ADVANCES AND CHALLENGES IN THE IMPLEMENTATION PROCESS OF \\ THE NATIONAL SCHOOL FOOD PROGRAM (PNAE) AND THE MONEY \\ DIRECT PROGRAM IN SCHOOL (PDDE)
}

\author{
Michelle Fernandes LIMA ${ }^{1}$ \\ Miriane Soares de OLIVEIRA ${ }^{2}$ \\ Andriele Petrouski GUARDACHESKI ${ }^{3}$
}

RESUMO: Este artigo apresenta os resultados de uma investigação realizada no curso de Pedagogia (Unicentro/Irati-PR), pesquisa vinculada ao Grupo de Pesquisa Estado, Políticas e Gestão da Educação. Teve como objetivo identificar os principais avanços e desafios no processo de implementação e gestão de dois programas federais: Alimentação Escolar (PNAE) e Dinheiro Direto na Escola (PDDE) na Rede Estadual de Ensino de Irati-PR. Consideramos nessa pesquisa as orientações legais para a efetivação desses programas, informações disponíveis nos sites do Fundo Nacional de Desenvolvimento da Educação (FNDE) e da Secretaria de Estado da Educação/ Governo do Paraná (SEED). Para complementar o estudo realizamos entrevistas com diretores de duas escolas estaduais, além de entrevista com a gestora do Núcleo Regional de Educação do Município, responsável pelos programas.

PALAVRAS-CHAVE: Gestão escolar. Programas Federais. Programa Nacional de Alimentação Escolar (PNAE). Programa Dinheiro Direto na Escola (PDDE).

\begin{abstract}
This article presents the results of an investigation performed at the Pedagogy course (Unicentro/Irati-PR), a research attached to the State, Politics and Education Management Research Group. It had as objective the identification of the main advances and challenges in the management and implementation process of two federal programs: School Meals (PNAE) and Money Straight to the School (PDDE) in the Tuition State Network of Irati$P R$. We considered in this research the legal orientations to the effectuation of these programs, information available in the websites of the National Fund of Education Development (FNDE) and of the State Secretary of Education/ Government of Paraná (SEED). To fulfill the study, interviews with the principals from two state schools were performed, aside from an interview with the manager of the City's Regional Education Nucleus, responsible for the programs.
\end{abstract}

KEYWORDS: School Management. Federal Programs. National Program of School Meals (PNAE). Money straight to the School Program (PDDE).

1 Professora do Departamento de Pedagogia e do Programa de Pós Graduação em Educação da Universidade Estadual do Centro Oeste: Campus Irati (PR)/ Líder do grupo de pesquisa- Estado, Políticas e Gestão da Educação: mfernandeslima@yahoo.com.br

${ }^{2}$ Pedagoga pela Universidade Estadual do Centro Oeste: mrianeoliveira31@ gmail.com

${ }^{3}$ Pedagoga pela Universidade Estadual do Centro Oeste: andripetrouski@ hotmail.com 


\section{Introdução}

A partir de estudos sobre as políticas de financiamento da educação e informações disponíveis no site do FNDE, é possível verificar que os Programas Nacional de Alimentação Escolar (PNAE) e Dinheiro Direto na Escola (PDDE) apresentaram alterações nas últimas décadas. O objetivo dessa pesquisa foi conhecer o funcionamento e a gestão dos programas mencionados na Rede Estadual de Ensino do Município de Irati, bem como, apontar avanços e desafios no processo de implementação dos mencionados programas.

A contribuição de Shiroma, et al (2005), foi o ponto de partida para o estudo, pois a luz das autoras entendemos que para uma política educacional ser implantada é importante considerar a influência de grupos sociais num processo de disputa no âmbito da sociedade civil. Reconhecemos também que os documentos não são aplicáveis a todos os contextos, assim a implantação de uma política exige ser adaptada de acordo com as mudanças que ocorrem em cada lugar.

Ainda nos moldes das autoras, nota-se que para os textos de políticas serem compreendidos é necessário considerar a forma como o texto é interpretado pelo receptor, pois assim, pode-se produzir um debate com outras leituras possibilitando muitas vezes uma interpretação mais completa. O que acaba resultando em um espaço maior para as diferentes interpretações e adequação ao contexto vivenciado em cada local é o que as autoras deixam claro no trecho a seguir:

Textos devem ser lidos com e contra outros, ou seja, compreendidos em sua articulação ou confronto com outros textos. Tal movimento, que fecunda o campo da educação com discursos produzidos em outros campos discursivos, demarca um novo terreno de analise [...] (SHIROMA e CAMPOS, 2005, p. 5).

A presente pesquisa apontou para a necessidade de entender o financiamento da educação pública, as chamadas políticas públicas de financiamento. Tendo como referência o artigo 212 da Constituição de 1988, que determina que a União destine anualmente no mínimo $18 \%$ na educação e os Estados, Distrito Federal e municípios, $25 \%$ de impostos derivados de transferências, na manutenção e desenvolvimento do ensino. 
Verificamos no site do $\mathrm{FNDE}^{4}$, que o Programa Nacional de Alimentação Escolar (PNAE) atende todos os alunos da Educação Básica matriculados em escolas públicas, filantrópicas e em entidades comunitárias (conveniadas com o poder público). Seu objetivo é atender as necessidades nutricionais dos alunos da Educação Básica.

Este programa é coordenado nacionalmente pelo Fundo Nacional de Desenvolvimento da Educação (FNDE) que repassa recursos financeiros aos estados e municípios para aquisição de alimentos que são destinados para a alimentação escolar. Foi implantado no ano de 1955 e definido como PNAE no ano de 1979. A partir da Lei $\mathrm{n}^{\circ} 11.947$ de 16 de junho de 2009, 30\% dos recursos repassados pelo FNDE para alimentação escolar passam a ser utilizados para compra de produtos da agricultura familiar, com isso o PNAE pode ser uma possibilidade de fortalecimento aos agricultores familiares e hábitos alimentares saudáveis.

Com base nestes dados há uma preocupação em relação à alimentação escolar, em que $30 \%$ das verbas são destinados direto aos municípios, portanto ocorre a descentralização desses recursos.

Já o Programa Dinheiro Direto na Escola (PDDE), tem o propósito de oferecer as escolas autonomia para utilizarem a verba proveniente do programa. Teve início em 1995, no governo de Fernando Henrique Cardoso. Inicialmente chamava-se Programa de Manutenção e Desenvolvimento do Ensino Fundamental (PMDE) tinha como objetivo financiar despesas de custeio. Conforme Brasil (2006a), a partir da Medida Provisória $\mathrm{n}^{\circ} 1.784$, de 14 de dezembro de 1998, o PMDE passou a ser denominado Programa Dinheiro Direto na Escola (PDDE).

No início o recurso era repassado às Secretarias de Educação a qual distribuía para as escolas, a partir de 1997, foi estabelecido como pré-requisito para o recebimento da verba, que as escolas com mais de 50 alunos criassem Unidades Executoras (UEx) ${ }^{5}$.

$\mathrm{O}$ recurso do PDDE vem em uma conta criada pelo Fundo Nacional de Desenvolvimento da Educação (FNDE) no nome da Associação de Pais, Mestres e Funcionários (APMF) de cada escola. Com base em informações do Portal do FNDE (BRASIL, 2014), o recurso é repassado uma vez por ano. O valor é calculado, com base no número de alunos matriculados na escola, segundo o Censo Escolar do ano anterior.

${ }^{4}$ <http://www.fnde.gov.br/programas/alimentacao-escolar/alimentacao-escolar-apresentacao>. Acesso 02 out.2014.

5 A Unidade Executora (UEx) é uma entidade privada sem fins lucrativos, integrada por membros da comunidade escolar, que define como a verba do PDDE deve ser administrada. 
$\mathrm{Na}$ primeira parte do artigo apresentamos os principais avanços e desafios do PNAE. Na segunda contemplamos os resultados observados no estudo sobre o PDDE na rede estadual de ensino de Irati (PR). Nos amparamos em pesquisas já realizadas, nas orientações legais, levantamento de dados quantatitvos sobre os programas, e ainda, entrevista com gestores para identificar os principais avanços e limites para a efetivação dos programas.

\section{Programa Nacional de Alimentação Escolar (PNAE): funcionamento, avanços e desafios}

Para verificarmos como ocorrem as políticas de financiamento da educação no Brasil, especialmente em relação ao PNAE, nos amparamos na LDB 9394/96, Constituição Federal de 1988, lei n 11.947 de 16/6/09, assim como nos autoras Ednir, Bassi (2009) e Costa (2013) que já escreveram a respeito deste assunto ${ }^{6}$.

Os artigos 211 e 212 da Constituição Brasileira orienta que o financiamento da educação, “a União, os Estados, o Distrito Federal e os Municípios organizarão em regime de colaboração seus sistemas de ensino". A União aplicará anualmente 18\% de seus impostos e transferências aos Estados, Distrito Federal e Municípios e 25\% para a manutenção e desenvolvimento do ensino.

Vale lembrar que este montante é advindo de impostos e também do Salário Educação, em que o artigo $1^{\circ}$ da lei $\mathrm{n}^{\circ} 4.440^{7}$ diz que estes recursos são instituídos pelas empresas que estão vinculadas com a Previdência Social, representado pelo custo do ensino primário dos filhos de seus empregados e suplementar as despesas públicas com a educação. Portanto baseados em Ednir, Bassi (2009, p.40), podemos dizer que a verba destinada para as políticas públicas, como a educação, é resultado de tributos diretos e indiretos que os trabalhadores pagam.

No ano de 1996, a Emenda Constitucional n 14 alterou o artigo 211 já mencionado e também o 214, criando o $\mathrm{FUNDEF}^{8}$ que teve um significado muito grande para os educadores na luta por educação pública. Entretanto, o fundo foi

\footnotetext{
${ }^{6}$ Foram consultadas também a lei ${ }^{\circ} 4.440$ de 27 de outubro de 1964 que institui o salário educação e a lei $n^{\circ} 9.424$ de 24 de dezembro de 1996 que dispões sobre o Fundo de Manutenção e Desenvolvimento de Ensino Fundamental e Valorização do Magistério (FUNDEF). Outros estudos sobre financiamento podem ser citados como Farenzena (2013), e Colly (2010).

${ }^{7}$ Lei de 27 de outubro de 1964 que institui o salário educação.

${ }^{8}$ Fundo de Manutenção e Desenvolvimento de Ensino Fundamental e valorização do magistério.
} 
regulamentado pela lei $\mathrm{n}^{\circ} 9.424 / 1996^{9}$, mais ainda não contemplou todas as etapas da educação básica segundo definição dos artigos $4^{\circ}, \S 1^{\circ}$; e art. $5^{\circ}$ da LDB, pois atendia somente o ensino fundamental e a valorização do magistério. Dez anos mais tarde, a Emenda Constitucional $\mathrm{n}^{\circ} 53$ substitui o FUNDEF pelo FUNDEB (Fundo de Manutenção e Desenvolvimento da Educação Básica), que conforme os artigos da LDB acima citados atende educação infantil, ensino fundamental e ensino médio.

Ainda nos moldes de Ednir, Bassi (2009 p. 57), ressaltamos que o FNDE conta com recursos de impostos, salário educação e também com recursos advindos das loterias, concursos e das verbas provenientes da Desvinculação das Receitas da União (DRU). É responsável também pela transferência aos programas atendidos como o PDDE em que dá assistência financeira as escolas da rede pública, para o PNAE realizando transferência financeira aos estados e municípios destinados a alimentação escolar. Atende o Brasil Alfabetizado, o (PNATE) e o Apoio ao atendimento à educação de Jovens e Adultos (Fazendo escola/ Peja).

Como estes recursos públicos federais são repassados aos estados e municípios, ocorre um processo de descentralização, que Costa (2013) considera uma forma de fortalecer estes entes federados e aperfeiçoar os gastos públicos com a educação. E ressalta ainda que:

\begin{abstract}
Descentralizar por descentralizar não resolve nada. Ou a descentralização é útil e frutificante, gerando resultados administrativos favoráveis, trazendo proveitos reais à atuação pública, ou será imprestável, até prejudicial (UCHÔA, 1984, apud COSTA, 2013, p.90).
\end{abstract}

Este programa deve garantir a alimentação escolar de todos os alunos da educação básica, que estão matriculados nas escolas públicas e filantrópicas. Seu objetivo é atender as necessidades nutricionais dos alunos durante o período que estão na escola. O repasse de recursos para a efetivação do programa é realizado diretamente aos estados e municípios, baseados no censo escolar que é realizado no ano anterior. Este programa é fiscalizado pela sociedade em geral, pelo Conselho de Alimentação Escolar (CAE), Tribunal de Contas da União (TCU), FNDE, Controladoria Geral da União (CGU) e também pelo Ministério Público.

${ }^{9}$ Lei de 24 de dezembro de 1996, que dispões sobre o Fundo de Manutenção e Desenvolvimento de Ensino Fundamental e valorização do magistério. 
O FNDE faz a transferência de recursos financeiros originados do Tesouro Nacional e assegurados no orçamento da União, às Entidades Executoras (EE) podendo ser os Estados, Distrito Federal e Municípios. Essa transferência é realizada em dez parcelas mensais em contas correntes específicas abertas pela autarquia ${ }^{10}$. Inicia-se a transferência no mês de fevereiro, atendendo 200 dias letivos, portanto cada parcela corresponde a vinte dias de aula ${ }^{11}$.

O valor transferido para as EEx é calculado da seguinte maneira: Valor do recurso mensal igual ao número de alunos constantes no censo escolar multiplicado por 20 dias letivos de atendimento. ${ }^{12}$

Percebemos na tabela $\mathrm{n}^{\circ} 1$ o valor repassado atualmente aos Estados e Municípios por dia letivo, que se define de acordo com a etapa de ensino.

Tabela 1: Valores para cada modalidade de ensino

\begin{tabular}{l|c}
\hline \multicolumn{1}{c|}{ Modalidade de Ensino } & $\begin{array}{c}\text { Valor por } \\
\text { aluno por dia }\end{array}$ \\
\hline Creches e ensino Integral & $\mathrm{R} \$ 1,00$ \\
Pré-escola e contra turno & $\mathrm{R} \$ 0,50$ \\
Ensino Fundamental, Médio e EJA & $\mathrm{R} \$ 0,30$ \\
Escolas Indígenas e Filantrópicas & $\mathrm{R} \$ 0,60$ \\
Ensino Integral (Mais Educação) & $\mathrm{R} \$ 0,90$ \\
\hline
\end{tabular}

Fonte: Dados organizados pelas autoras com base nos dados do site do FNDE ${ }^{13}$

Ao consultar o site da Secretaria Estadual de Educação ${ }^{14}$, constatamos que o município de Irati na Rede Estadual de ensino possui 16 escolas públicas, tendo 7.490 alunos matriculados, dados atualizados em setembro de 2014. O orçamento do programa para o atendimento de todos os alunos da rede pública no ano de 2014 foi de 3,6 bilhões destinados ao PNAE, que beneficiam 42 milhões de estudantes da educação básica. A lei $\mathrm{n}^{\circ} 11.947$ prevê que 30\% desse valor sejam investidos na compra de produtos da agricultura familiar.

10 “Empresa ou órgão autônomo da administração pública". (ROCHA, 1931, p.66)

11 <http://www.gestaoescolar.diaadia.pr.gov.br/modules/conteudo/conteudo.php?conteudo=156> Acesso 02 out. 2014.

${ }^{12}$ Fonte: <http://www.fnde.gov.br/programas/alimentacao-escolar/alimentacao-escolar-apresentacao>. Acesso 02 out.2014.

13 Fonte: <http://www.fnde.gov.br/programas/alimentacao-escolar/alimentacao-escolar-apresentacao>. Acesso 02 out.2014.

${ }^{14}$ http://www.nre.seed.pr.gov.br/irati. Acesso 10 out.2014. 
A rede Estadual de Ensino de Irati é composta por 16 escolas, que atendem 7490 alunos do ensino fundamental e médio. Todas essas instituições recebem os alimentos da agricultura familiar previstos na Lei 11.947 de 2009. Elencamos na tabela 2 as escolas e o número de alunos atendidos por cada uma delas no ano de 2014.

Tabela 2: Escolas e número de alunos da Rede estadual de Educação de Irati

\begin{tabular}{lc}
\multicolumn{1}{c}{ Escolas Estaduais } & $\mathbf{N}^{\circ}$ de alunos \\
\hline Centro Est. de Educação Profissional Pres. & \\
Costa e Silva & 401 \\
Colégio Est. Antônio Xavier da Silveira & 1297 \\
Colégio Estadual Duque de Caxias & 483 \\
Colégio Estadual João de Mattos Pessoa & 465 \\
Colégio Estadual João XXIII & 677 \\
Colégio Estadual Nossa Senhora de Fátima & 448 \\
Colégio Estadual Pio XII & 339 \\
Colégio Estadual Rio do Couro & 217 \\
Colégio Estadual São Vicente de Paulo & 702 \\
Colégio Estadual Trajano Grácia & 397 \\
Escola Estadual Antônio Lopes Jr. - CAIC & 189 \\
Escola Estadual de Gonçalves Jr. & 216 \\
Escola Estadual Pedro Baltzar & 151 \\
Escola Estadual Luíza Rosa Zarpellon Pinto & 301 \\
Escola Estadual Nossa Senhora das Graças & 627 \\
CEEBJA & 580 \\
\hline TOTAL & 7490 \\
\hline
\end{tabular}

Fonte: Dados organizados pelas autoras, com base nas informações disponíveis no site do FNDE $^{15}$

Para o desenvolvimento deste trabalho, selecionamos duas das escolas citadas na tabela 2, uma de grande e outra de pequeno porte. Estas instituições serão caracterizadas como 1 e 2 , sendo a 1 de pequeno e a 2 de grande porte e as gestoras entrevistadas serão denominadas de $\mathrm{A}$ e $\mathrm{B}$.

Em contato com o Núcleo Regional de Educação de Irati tomamos conhecimento do funcionamento do PNAE neste município. Sendo coordenado pela Secretaria Estadual de Educação (SEED), especificamente pela Superintendência de Desenvolvimento Educacional (SUDE), que atende todos os núcleos do estado do Paraná.

O Núcleo Regional de Educação de Irati atende os munícipios: Fernandes Pinheiro, Guamiranga, Inácio Martins, Mallet, Prudentópolis, Rebouças, Rio Azul e

${ }^{15}$ Disponível em:

<http://www.consultaescolas.pr.gov.br/consultaescolas/f/fcls/estado/escolas/endereco.xhtml> Acesso em: 28 jul. 2015. 
Teixeira Soares. Como responsável pelo PNAE nestas regiões, o Núcleo conta com uma funcionária efetiva que dá assistência as escolas e também aos agricultores.

A gestora do programa nos repassou que a SUDE por meio de edital de chamada pública, faz a seleção de cooperativas e associações representativas de agricultores familiares para o fornecimento de gêneros alimentícios, estes que são entregues diretamente nos endereços dos estabelecimentos escolares da rede pública estadual de ensino do Paraná.

Para o ano de 2014, o edital de chamada pública 001/2014- SEED/SUDE selecionou para o município de Irati duas associações que forneciam através dos agricultores os alimentos as escolas, contudo, uma delas não atingiu a sua demanda de alimentos, ficando somente uma associação para atender a toda rede estadual de ensino deste município.

A SEED/SUDE possui um relatório anual de atendimento da merenda escolar, tivemos, portanto acesso aos dados de 2014 da distribuição descentralizada (Agricultura Familiar) do núcleo de Irati. Foram atendidos 9 municípios, 63 estabelecimentos, 23.869 alunos, $210.089,311 \mathrm{~kg}$ de gêneros alimentícios e um montante de $\mathrm{R} \$$ 902.396,66. Este valor em dinheiro corresponde aos 30\% previstos na Lei $n^{\circ}$ 11.947/09.

A partir das entrevistas realizadas destacamos os seguintes pontos: avanços, desafios, capacitação, relação escola/agricultor e se ocorreu melhora na merenda escolar a partir da efetivação da Lei $\mathrm{n}^{\circ} 11.947 / 09$. Pela análise das informações obtidas, consideramos que os dados de maior relevância e no que se refere às escolas é a quantidade, qualidade e a relação com a agricultura familiar.

Apresentamos a seguir as questões identificadas nas pesquisas em contraponto com a literatura disponível sobre a temática, além disso, buscamos relacionar esses dados com a realidade das escolas entrevistadas.

Sobre os avanços do programa, a escola 1 aponta a melhora na qualidade e quantidade de merenda, sendo que em anos anteriores a gestora buscava merenda em outras escolas para complementar e servir aos alunos, atualmente isso não acontece. A escola 2 também destaca melhora na qualidade dos alimentos, e uma variação, tendo frutas e verduras na alimentação diária.

Para a gestora do núcleo um dos avanços do programa foi a promulgação da Lei $\mathrm{n}^{\circ} 11.947 / 09$, que incentiva a agricultura familiar e estimula o desenvolvimento econômico e sustentável, contribui também com alimentos frescos como frutas, verduras e vegetais na alimentação escolar. 
Já o desafio observado pela gestora A é manter a quantidade e principalmente a qualidade dos alimentos. Para a B também é a qualidade, ambas relataram que no inicio das entregas dos alimentos pelos agricultores, alguns produtos vieram em má qualidade, que foi substituído após o contato da escola com a associação que representa os agricultores.

A gestora do núcleo considera que o grande desafio é o processo de compra da agricultura familiar, pois no Paraná, são 399 municípios e mais de 2500 estabelecimentos de ensino, cada um com uma particularidade de cardápio, em que é necessário planejar e adquirir alimentos para as entregas semanais, respeitando os hábitos de cada região.

Notamos aqui uma ligação com o relato de uma nutricionista, que consta na pesquisa de Anjos et al (2014) sobre a dificuldade de adaptar as exigências nutricionais com a oferta dos produtos de agricultura local. A entrevistada destaca também que "outra dificuldade é a não contratação de nutricionistas para supervisão in loco nas escolas”. Sendo que a Resolução CFN n 465/10 diz que o parâmetro numérico é de um nutricionista para cada 2.500 alunos.

Observa ainda como desafio manter ou ampliar a aquisição de gêneros da agricultura familiar com o pequeno recurso que o governo federal tem enviado, e que desde o ano de 2010 não foi reajustado, mesmo com toda a inflação dos alimentos. Lembrando que o repasse para a rede estadual é de $\mathrm{R} \$ 0,30$ por aluno/dia.

Perguntamos a gestora como são organizados os cardápios, ela nos repassou que são organizados pelas nutricionistas da SUDE/DILOG/CANE ${ }^{16}$, não por regiões e sim em nível de estado, sendo que cada escola pode elaborar o seu próprio cardápio, avaliado pelo núcleo e aprovado pela SUDE.

Outro ponto importante a ser destacado é que segundo a gestora, em Irati não possuímos nutricionistas para atender o município, a não ser a nutricionista a nível de estado. O município conta apenas com dois técnicos que possuem formação diversificada, e realizam somente análise técnica.

Observamos aqui uma primeira irregularidade, pois se a Resolução CFN n 465/10 diz que é necessário um nutricionista para cada 2500 alunos, somente para o Município de Irati seriam necessários 3 nutricionistas, sendo que contamos apenas com os técnicos.

16 Superintendência de Desenvolvimento Educacional (SUDE); Diretoria de Infraestrutura, Logística, Organização e Gestão (DILOG); Coordenação de Alimentação e Nutrição Escolar (CANE). 
No quesito capacitação perguntamos aos gestores: Você já participou de algum tipo de capacitação sobre a alimentação escolar? A resposta da gestora A foi somente orientações, "nós temos algumas reuniões, há um repasse de informações inclusive da lei e como a gente deve gerir todo esse processo, mas uma capacitação diretamente não”. Ao contrário da gestora A, a B afirma que a escola participou, mas não a direção, como esta escola é de grande porte, uma funcionária é responsável pela merenda, esta já teve uma capacitação.

Percebemos que as respostas das gestoras das escolas 1 e 2 se contradizem, de fato ocorreu ou não esta capacitação? Na resposta do núcleo, confirmamos que são realizadas reuniões com os gestores e agricultores para o repasse de informações sobre o programa.

Concordamos com Anjos et al (2014) ao dizer que não houve o cumprimento de uma das atividades do programa, pois é determinado por lei que sejam realizados treinamentos de acordo com as necessidades de cada instituição. Assim também Costa (2013) ressalta que um dos desafios do PNAE a ser vencido é a capacitação técnica dos gestores do programa nos municípios.

Por meio desses dados e observando o artigo 13 inciso $3^{\circ}$ da Resolução $n^{\circ}$ 38/16/6/2009 já citados anteriormente, alegamos que em nossa realidade não acontece a efetivação dessa atividade, pois este artigo diz que o FNDE promoverá Centros Colaboradores que possam prestar apoio técnico e operacional na implementação da alimentação saudável e desenvolvimento de ações para uma boa execução do PNAE.

Fica evidente a ausência de capacitações completas envolvendo principalmente os gestores escolares, visto que ambas as gestoras das escolas entrevistadas nos repassaram que há um funcionário responsável por receber os alimentos. Em conversa com um desses funcionários, ele nos afirma que não tem contato com os agricultores, pois ele somente assina a nota e quem recebe os gêneros alimentícios é a merendeira.

Outra questão posta aos gestores foi: Como se dá a relação da escola/ fornecedores de alimentos da agricultura familiar? A resposta da A foi, que teve problemas somente no início, vindo alimentos estragados e diferentes da lista. Na nota estava descrito um produto e vinha outro, então a escola não recebia, não assinava a nota, até que o produto fosse trocado. "Mas isso aconteceu somente no início do programa". E o último ponto destacado na pesquisa: Você observa melhoria na alimentação a partir da Lei ${ }^{\circ} 11.947 / 09 ?$ 
A resposta da gestora $\mathrm{A}$ foi que melhorou a qualidade e a quantidade, a qualidade porque tivemos a agricultura familiar, então teve uma diversidade de alimentos, frutas, verduras, vegetais que nós não tínhamos e agora temos. Para a B, "sim, houve uma melhoria, um cuidado maior".

Lembramos que as palavras de maior destaque nas entrevistas foram qualidade e quantidade. De fato percebe-se nas expressões das gestoras que houve uma melhora nestes quesitos a partir da efetivação da Lei n 11. 947/09, ou seja, do ano 2010 até agora.

Contudo a relação escola/fornecedor de alimentos deixa a desejar, pois ambos os gestores (diretores) relataram problemas no início das entregas dos alimentos. E também destinam um funcionário para o recebimento destes alimentos, sendo que um deles relatou somente assinar a nota. Então este funcionário que é destinado para conferir a mercadoria com o que está na nota passa sua responsabilidade para a merendeira, pois afirmou somente assinar a nota.

Ao que parece, nas escolas entrevistadas a Lei $\mathrm{n}^{\circ}$ 11.947/09 trouxe melhorias na alimentação, entretanto ainda há alguns empasses que necessitam ser averiguados, como uma boa capacitação do gestor escolar e dos funcionários envolvidos no recebimento dos alimentos, assim como a necessidade da contratação de nutricionistas.

\section{Programa Dinheiro Direto na Escola (PDDE): funcionamento, avanços e desafios}

Assim como o PNAE, uma das principais características do PDDE é a descentralização e como consequência a denominada autonomia financeira. As escolas recebem o dinheiro e analisam suas necessidades, bem como verificam se aqueles determinados produtos podem ser adquiridos, respeitando as normas que o programa determina.

O PDDE assim como outros programas federais recebem verbas do Salário Educação, sendo que este é uma contribuição social cobrada das empresas. Desde 1964 as empresas são obrigadas a recolher $2,5 \%$ calculados sobre o valor da folha de pagamento dos funcionários. Até 2005, esse valor era destinado unicamente ao ensino fundamental. Assim, a Emenda Constitucional 53/2006 no seu artigo 212, inciso $5^{\circ}$ regulamenta o Salário Educação “A educação básica pública terá como fonte adicional 
de financiamento a contribuição social do Salário Educação, recolhido pelas empresas na forma da lei” (BRASIL, 2006b).

A partir dos estudos é possível identificarmos que PDDE foi criado com o propósito de descentralizar os recursos, outra característica do programa é a autonomia oferecida as escolas com o envio do recurso para as mesmas. Santos (2006), relata que o PDDE oferece as escolas uma autonomia relativa. Pois a escola pode gastar o dinheiro em algumas despesas que já veem predestinadas. Sendo que os recursos resolvem os problemas imediatos da escola.

Conforme informações do site do FNDE (BRASIL, 2014) o valor total de cada unidade de ensino será calculado pela soma de dois valores: o valor fixo - conforme o tipo de estabelecimento - e o valor variável - conforme o número de alunos. Escola pública urbana com UEx - R\$ 1.000,00; Escola pública rural com UEx - R \$ 2.000,00; Escola privada de educação especial - R \$ 1.000,00; Polo presencial da UAB - R\$ $3.000,00$.

Já o valor variável é calculado multiplicando-se o número de alunos conforme o Censo Escolar do ano anterior pelos valores per capita.

Tabela 02: Valores por aluno

\begin{tabular}{lll}
\hline & \multicolumn{1}{c|}{ Alunos } & Per capita \\
\hline UEx & Aluno de escola urbana ou rural com & $\mathrm{R} \$ 20,00$ \\
& Aluno de escola urbana sem UEx & $\mathrm{R} \$ 40,00$ \\
& Aluno de escola rural sem UEx & $\mathrm{R} \$ 60,00$ \\
& Aluno da educação especial em escola & $\mathrm{R} \$ 80,00$ \\
pública & & $\mathrm{R} \$ 60,00$ \\
& Aluno da educação especial em escola & $\mathrm{R} \$ 20,00$ \\
\hline
\end{tabular}

Fonte: As autoras.

Na pesquisa contemplamos duas escolas, que serão denominadas como A e B. A Escola A, foi inaugurada no dia 03 de março de 1975, está localizada na região do central de Irati. Oferece Ensino Fundamental Anos Finais, Ensino Médio e Curso de Formação na Modalidade Integrado e Subsequente. 
A equipe pedagógica da escola é composta por um diretor, dois diretores auxiliares, três pedagogas, dez auxiliares administrativos; sendo que oito atuam na secretaria da escola e dois na biblioteca, nove serviços gerais.

$\mathrm{Na}$ Escola A há três órgãos colegiados: APMF, Conselho Escolar que é composto por 26 membros. Sendo 14 professores e funcionários da instituição, 4 pais de alunos, 6 alunos da escola e 2 membros da sociedade civil. O Grêmio Estudantil da instituição é composto por 10 alunos.

Conforme a tabela 03, esta escola recebe recursos do PDDE, Atleta na Escola e ProEMi.

Tabela 03: Valores Recebidos Pela Escola A $2014^{17}$

\begin{tabular}{l|c}
\hline \multicolumn{1}{c|}{ Programa } & $\begin{array}{c}\text { Valor } \\
\text { recebido }\end{array}$ \\
\hline PDDE & $\mathrm{R} \$ 29.120,00$ \\
ATLETA NA ESCOLA & $\mathrm{R} \$ 3.829,00$ \\
PROEMI & $\mathrm{R} \$ 60.000,00$
\end{tabular}

Fonte: As autoras.

Já a escola B foi inaugurada em Irati no ano de 1973, conta com um espaço de $175 \mathrm{ha}^{18}$. Juntamente com a escola, há o curso de Técnico em Floresta Subsequente, Técnico Floresta Internato, Técnico em Meio Ambiente Subsequente e Técnico em Segurança do Trabalho.

A equipe da escola é formada por 61 funcionários, 38 professores e atendem um total de 431 alunos. Os órgãos colegiados que funcionam na escola são: APMF e o Conselho Escolar. Conforme um funcionário desta escola me informou a APMF do colégio é formada apenas por professores, funcionários da escola. Não prevê a participação de pais. O Conselho Escolar é formado por 20 integrantes. Esta escola assim como a anterior também recebe recursos do PDDE, Atleta na Escola e ProEMi.

${ }^{17}$ Esses dados foram retirados do site do FNDE (BRASIL, 2015) e compilados.

${ }^{18}$ Hectare. 
Tabela 04: Valores Recebidos Escola B $2014^{19}$

\begin{tabular}{l|c}
\hline \multicolumn{1}{c|}{ Programa } & \multicolumn{1}{c}{$\begin{array}{c}\text { Valor } \\
\text { recebido }\end{array}$} \\
\hline PDDE & $\mathrm{R} \$ 5.260,00$ \\
ATLETA NA ESCOLA & $\mathrm{R} \$ 1.381,00$ \\
PROEMI & $\mathrm{R} \$ 42.000,00$ \\
\hline
\end{tabular}

Fonte: As autoras.

A partir das entrevistas realizadas destacamos pontos como: avanços, desafios, orientações repassadas as Unidades Executoras, processo de prestação de contas, participação da comunidade escolar e a contribuição do programa para a escola. Pela análise das informações obtidas consideramos que o dado de maior relevância no que se refere ao núcleo são as novas ramificações do PDDE e no que se refere às escolas é a autonomia.

Ao questionar a coordenadora do Núcleo sobre os avanços referentes ao Programa Dinheiro Direto na Escola ela apontou as novas ramificações do PDDE, explicando que desta forma as escolas podem receber mais recursos federais. Estas novas ramificações são as modalidades do PDDE: PDDE Água na Escola, PDDE Atleta na Escola, PDDE Escola do Campo, PDDE Escolas Sustentáveis, PDDE Mais Educação e Ensino Médio Inovador (PROEMI). Com essas modalidades as escolas recebem verbas para diversas finalidades. Porém é um processo burocrático. As escolas precisam manter o cadastro atualizado para assim poderem se encaixar nestes programas e receberem as verbas.

No que se refere aos desafios ela relatou que é específico de cada APMF, e afirmou "[...] a APMF não é ativa com os recursos federais". A coordenadora explicou que muitas vezes a APMF é representada apenas pelo presidente os demais integrantes não participam do processo de seleção da necessidades que a escola enfrenta.

As escolas recebem o dinheiro e ocorre uma reunião entre o diretor, comunidade escolar e a APMF para definirem o que a escola precisa, sempre considerando as normas impostas pelo programa.

O Guia de Orientações para a aquisição de materiais e bens de contratação de serviços com recursos do PDDE (BRASIL, 2011, p. 6) traz a seguinte orientação:

19 Esses dados foram retirados do site do FNDE (BRASIL, 2014) e compilados. 
Inicialmente, a UEx ou Entidades Mantenedoras (EM) beneficiária dos recursos do PDDE deverá realizar, com a participação de professores, pais, alunos, entre outros membros da comunidade escolar, o levantamento das necessidades prioritárias da escola que representa e a seleção dos materiais e bens e/ou serviços destinados a suprir essas necessidades.

Percebemos a importância dessa participação para a escolha dos materiais, não se limitando ao que o diretor da escola acha que precisa comprar. Pois com a participação de todos é possível conhecer a visão de cada integrante para a melhoria da escola.

No que se refere às orientações repassadas as UEx e processo de prestação de contas a coordenadora explicou que são repassadas as normas exigidas pelo programa. Essas normas precisam ser seguidas. Pois o descumprimento acarreta no não recebimento da verba no ano seguinte. Kalam (2011, p.87) explica que:

O PDDE estabelece as formas de utilização dos recursos: manutenção e conservação das escolas, aquisição de materiais para seu funcionamento, capacitação e aperfeiçoamento dos profissionais, avaliação da aprendizagem, implementação do projeto políticopedagógico, aquisição de material didático/pedagógico e desenvolvimento de atividades educacionais diversas. Com isso, define o leque de opções para o uso dos recursos, não garantindo às escolas, a partir de suas necessidades e prioridades, a liberdade de decidir sobre os gastos.

Ao questionarmos a diretora da escola A sobre os avanços do PDDE, ela destacou a autonomia oferecida pelo programa para as escolas para adquirir o que é necessário:

Isso é um avanço muito grande, do que você ter que esperar que o governo mande um computador, que o governo mande o giz, que o governo mande um ventilador pra colocar numa sala de aula. Sendo que o governo manda a verba e você pode administrar o dinheiro.

Santos (2006) afirma que a autonomia oferecida pelo programa é uma autonomia relativa, pois o recurso vem predestinado para as escolas. Sendo que o discurso do PDDE tem como principais características a descentralização financeira, a autonomia e a desburocratização.

A autonomia é um termo polissêmico - possui vários significados - sendo que o governo adotou este programa de descentralização para oferecer às escolas autonomia, 
porém é algo parcial. Por vezes as escolas tem outras necessidades prioritárias, mas a verba não pode ser utilizada. Então nos questionamos que autonomia é essa?

Notamos que o PDDE apresenta contribuições para as escolas. E como o coordenador do programa da escola B citou "É um recurso muito bom, sem ele as escolas não teriam como sobreviver". Porém precisamos refletir que autonomia é essa oferecida para as escolas e o valor do recurso é suficiente?

No discurso do coordenador do programa da escola B, é possível notar a falta do recurso financeiro nas nossas escolas. Mesmo o programa tendo as suas falhas, não oferecendo a autonomia total as escolas dependem deste dinheiro para se manter.

O coordenador do programa da escola B respondeu como avanços, as novas ramificações, sendo que assim a escola pode receber mais recurso federal.

A escola A, elencou como um desafio o atraso das parcelas, a diretora afirmou que ocorreram algumas situações de atrasar mais que já foi normalizado. Pinheiro (2012, p.26) comenta que "[...] as principais dificuldades encontradas na execução dos recursos do PDDE são os atrasos no envio dos recursos pelo FNDE para as unidades escolares, pois os repasses, geralmente, começam somente no segundo semestre de cada ano”. A escola B não respondeu esta questão.

Quando perguntamos aos entrevistados da escola A e B se ocorre a participação da comunidade no processo de seleção dos materiais e serviços que serão realizados com a verba, ambos afirmaram que ocorre a participação efetiva da comunidade escolar e da APMF.

Ocorrendo desta forma uma contradição, pois a coordenadora do PDDE no Núcleo apontou como um dos desafios a ausência da APMF neste processo referente ao dinheiro do programa.

Santana (2011) afirma que o Governo adota certas medidas tentando impor as escolas uma gestão participativa. Como no caso do PDDE, para as escolas receberem o dinheiro elas precisam criar UEx e os membros da mesma precisam ser ativos na escola.

Percebemos a participação da comunidade na escola como um ponto positivo em relação ao PDDE, para a escola desenvolver uma gestão democrática a comunidade escolar deve participar dos processos. A comunidade pode auxiliar no processo de seleção das prioridades e também verificar se a verba está sendo utilizada de forma coerente.

Outro ponto da nossa entrevista é quanto a de prestação de contas, ambas as escolas possuem um funcionário que realiza esta ação. Conforme os entrevistados é um 
processo lento. Pinheiro (2012) afirma que umas das dificuldades do PDDE é o processo de prestação de contas. "[...] Outra grande dificuldade são os procedimentos exigidos na prestação de contas dos recursos utilizados pelas escolas, que, muitas vezes, são complexos para os gestores escolares" (PINHEIRO, 2012, p. 26).

No caso das escolas entrevistadas, ambas possuem um funcionário que com o auxílio do diretor realizam este processo de prestação de contas.

A última questão da entrevista trata da contribuição do programa para a escola. A diretora da escola A respondeu: "[...] dá autonomia para que o diretor e a comunidade escolar possam decidir o que comprar. Não que você tenha uma autonomia total, é uma autonomia em partes".

Nota-se que a diretora reconhece que as escolas possuem uma autonomia parcial percebemos isso como um ponto positivo. Sendo que ela reflete sobre o discurso do PDDE. Diferentemente do coordenador do programa na escola B que não elencou a questão da autonomia. Para a escola B a contribuição do programa é que destina recursos para a aquisição de capital (bens duráveis).

A Lei $n^{\circ} 11.947$ no seu art. 23 define no que os recursos podem ser gastos e qual a finalidade:

Art. 23. Os recursos financeiros repassados para o PDDE serão destinados à cobertura de despesas de custeio, manutenção e de pequenos investimentos, que concorram para a garantia do funcionamento e melhoria da infraestrutura física e pedagógica dos estabelecimentos de ensino (BRASIL, 2009a).

Percebemos a contribuição do programa para as escolas, porém será que o recurso destinado, com todo o processo de burocratização para utilização da verba garante o funcionamento e melhoria da infraestrutura física e pedagógica dos estabelecimentos de ensino?

\section{Considerações finais}

Buscamos nessa pesquisa, conhecer o funcionamento dos Programas PNAE e PDDE, não em sua totalidade, mas em duas escolas estaduais do Município de Irati.

Percebemos pelas entrevistas realizadas indicativos sobre os principais desafios para a efetivação dos programas mencionados. No que se refere ao PNAE, destacamos 
os seguintes aspectos: a capacitação da equipe completa envolvida no programa, sendo os diretores escolares, nutricionistas, agricultores, merendeiras e os funcionários das escolas responsáveis pelo recebimento dos alimentos advindos da agricultura familiar. Além disso, observamos o não reajuste do montante destinado a rede estadual que é de $\mathrm{R} \$ 0,30$ por dia/aluno, mesmo com toda a inflação dos alimentos. E a falta de nutricionista para a supervisão direta nas escolas.

Como o PNAE é um programa federal que atende os alunos da rede pública de educação de nosso país, observamos nas pesquisas já concluídas em outros estados, que também existem lacunas a serem superadas, tais como: a dificuldade da oferta de alimentos frescos e de boa qualidade em todas as entregas, assim como o despreparo por parte dos agentes envolvidos no programa.

Segundo o FNDE o objetivo do PNAE é contribuir para o desenvolvimento da aprendizagem e a formação de hábitos alimentares saudáveis dos alunos, oferecendo refeições que garantam as necessidades nutricionais durante o período que estão na escola. Com a implementação da Lei 11.947, tudo se encaminha para que o programa alcance seu objetivo, contudo é necessária ainda uma avaliação por parte dos poderes públicos a respeito da efetivação deste programa, pois os desafios necessitam ser superados para considerarmos uma política pública que de fato atenda com qualidade as demandas nutricionais dos alunos.

Sobre o PDDE, a partir das leituras realizadas e das entrevistas percebemos que o programa apresenta benefícios às escolas, pois as instituições ao receberem o dinheiro podem adquirir bens duráveis e não duráveis, seguindo as orientações sobre o que comprar. É notável que o programa aponta um discurso de descentralização do dinheiro e autonomia para as escolas optarem no que irão gastar a verba. Porém essa realidade, não se concretiza completamente. As escolas não possuem a autonomia efetiva para adquirir os produtos, é uma autonomia parcial.

É importante salientar que não temos a pretensão de generalizar as questões referentes ao PDDE e o PNAE, deixamos claro que o nosso objetivo com este estudo foi conhecer a gestão dos programas, bem como, apontar alguns desafios para sua implementação. Compreendemos que cada região possui um contexto diferente e com isso suas especificidades.

No decorrer do estudo algumas questões foram levantadas como: descentralização, a autonomia, a participação da comunidade neste processo da gestão do PDDE, novas ramificações. Percebemos que estas questões são similares a outros 
trabalhos que utilizamos neste estudo. Não tivemos por objetivo avaliar ou apontar falhas, buscamos conhecer o programa e apontar alguns avanços e desafios no processo de implementação no cenário das escolas estaduais de Irati (PR).

\section{Referências}

ANJOS, Daniela Araújo et al. O Programa Nacional de Alimentação Escolar sob a percepção dos gestores escolares do município de Viçosa-MG. In: Encontro Nacional de Pesquisadores em Gestão Social: Enapegs, 8, 2014, Bahia. Anais. Bahia: 2014. p. 114. Disponível em: <file:///C:/Users/cliente/Downloads/artigo\%20enapegs.pdf>. Acesso em 02 jul. 2015.

BRASIL. Constituição (1988). Constituição da República Federativa do Brasil. Brasília, DF: Senado Federal, 1988.

BRASIL. Lei $\mathbf{n}^{0}$ 9.424, de 24 de dezembro de 1996. Dispõe sobre o Fundo de Manutenção e Desenvolvimento do Ensino Fundamental e de Valorização do Magistério. Diário Oficial da União, Brasília, 1996. Disponível em <http://www.planalto.gov.br/ccivil_03/leis/L9424compilado.htm>. Acesso em: $10 \mathrm{fev}$. 2015

BRASIL. Lei $\mathbf{n}^{\circ}$ 11.947, de 16 de junho de 2009. Dispõe sobre o atendimento da alimentação escolar e do Programa Dinheiro Direto na Escola aos alunos da educação básica. $\quad$ Brasília, 2009. Disponível em: http://www.planalto.gov.br/ccivil_03/_ato2007-2010/2009/lei/l11947.htm>. Acesso em: 10 fev.2015

BRASIL. Fundo Nacional de Desenvolvimento da Educação. Resolução no 38, 16 de junho de 2009. Dispõe sobre o atendimento da alimentação escolar aos alunos da educação básica no Programa Nacional de Alimentação Escolar - PNAE. Brasília, 2009. Disponível em: <file:///C:/Users/cliente/Downloads/res038_16072009\%20(1).pdf>. Acesso em: 25 ago. 2014

BRASIL. Resolução CFN $\mathbf{n}^{\circ} \mathbf{4 6 5 / 2 0 1 0}$. Dispõe sobre as atribuições do Nutricionista, estabelece parâmetros numéricos mínimos de referência no âmbito do Programa de Alimentação Escolar PAE e dá outras previdências. Brasília, 2010. Disponível em: $<$ http://www.cfn.org.br/novosite/arquivos/Resol-CFN-465-atribuicao-nutricionistaPAE.pdf $>$. Acesso em: 10 fev. 2015

BRASIL. Lei n. 9.394, de 20 de dezembro de 1996. Estabelece as diretrizes e bases da educação nacional. Diário Oficial da União, Brasília, DF, 23 dez. 1996. Disponível em: <http://www.planalto.gov.br/ccivil_03/leis/19394.htm>. Acesso em: 08 nov. 2014.

BRASIL. Ministério da Educação. Secretaria de Educação a Distância. Módulo PDDE. 2. ed. atual. Brasília: MEC, 2006a. 
BRASIL. Constituição (1988). Emenda Constitucional n. 53, de 19 de dezembro de 2006. Dá nova redação aos arts. $7^{\circ}, 23,30,206,208,211$ e 212 da Constituição Federal e ao art. 60 do Ato das Disposições Constitucionais Transitórias. Diário Oficial da União, Brasília, DF, 20 dez. 2006b. Disponível em: <http://www.planalto.gov.br/ccivil_03/constituicao/Emendas/Emc/emc53.htm>. Acesso em: 25 ago. 2014.

BRASIL. Lei n. 11.947, de 16 de junho de 2009. Dispõe sobre o atendimento da alimentação escolar e do Programa Dinheiro Direto na Escola aos alunos da educação básica. Diário Oficial da União, Brasília, DF, 16 jun. 2009a. Disponível em: <http://www.planalto.gov.br/ccivil_03/_ato2007-2010/2009/lei/111947.htm>. Acesso em: 08 nov. 2014.

BRASIL. Manual de orientação para constituição de unidade executadora. Brasília, DF: [s.n.], 2009b.

BRASIL. Ministério da Educação. Guia de orientações escola: para aquisição de materiais e bens e contratação de serviços com recursos do Programa Dinheiro Direto na Escola - PDDE. Brasília, DF: MEC, 2011. Disponível em: <www.fnde.gov.br/index.php/ph.../5-2011?...no-9...232011-guia...>. Acesso em: 15 jul. 2015.

COSTA, Jordanna Maria Nunes. Política de Alimentação Escolar: Tem caroço nesse angu? A gestão e o controle social do PNAE. 2013. 185f. Dissertação (Mestrado em Educação) - Programa Mestrado Profissional em Educação, Universidade de Brasília. Disponível em: <http://repositorio.unb.br/bitstream/10482/15319/1/2013_JordannaMariaNunesCosta.pd f.> Acesso: 12 mai. 2014.

EDNIR, Madza; BASSI, Marcos. A legislação relativa à educação e ao seu financiamento. In: (Org.). Bicho de sete cabeças: para entender 0 financiamento da educação brasileira. São Paulo: Petrópolis, 2009. p. 37-69.

FARENZENA, Nalú; LUCE, Maria Beatriz. Financiamento da educação e responsabilidades federativas: 25 anos de agenda constituinte. RBPAE, [S.1.] v.29, $\mathrm{n}^{\circ} 2, \quad$ p.263-281, mai/ago.2013. Disponível em: <file:///C:/Users/cliente/Downloads/43523-174969-1-SM.pdf>. Acesso em: 20. fev.2015

PARANÁ. Edital de Chamada Pública $n^{\circ}$ 001/2014-SEED/SUDE. Disponível em $<$ http://www.educacao.pr.gov.br/arquivos/File/editais/edital0012014seedsude23maio.pd f>. Acesso em: 02 fev.2015

KALAM, Roberto Jorge Abou. O Programa Dinheiro Direto na Escola no contexto do financiamento público da educação: implementação de políticas e implicações na gestão escolar. 2011. 160 f. Dissertação (Mestrado em Educação), Universidade Federal de Juiz de Fora, Juiz de Fora, 2011. Disponível em: <http: /ufjf.br/ppge/files/2011/07/DISSERTA\%C3\%87\%C3\%83O.pdf.>. Acesso em: 28 jun. 2014. 
MENEZES, Raul Miranda. Processo de gastos e descentralização na política educacional brasileira. Em Aberto, v. 18, n.74, p. 58-71, dez. 2001. Disponível em: <http: /emaberto.inep.gov.br/index.php/emaberto/article/viewFile/1128/1027.>. Acesso em: 02 set. 2014.

PARANÁ. Governo do Estado do Paraná. Secretaria da Educação. Consulta Escolas. Disponível em: <http://www4.pr.gov.br/escolas/frmPesquisaEscolas.jsp>. Acesso em: 01 set. 2015.

PINHEIRO, Iara Ferreira. Programa Dinheiro Direto na Escola (PDDE) implicações na gestão, no financiamento e na qualidade do desempenho da educação básica: estudo de caso - modalidade tempo integral. 2012. 83 f. Dissertação (Mestrado em Educação) - Faculdade de Educação, Universidade Federal de Juiz de Fora, Juiz de Fora, 2012. Disponível em: <http: /www.mestrado.caedufjf.net/wpcontent/uploads/2014/02/dissertacao-2010-iara-ferreira-pinheiro.pdf.>. Acesso em: 28 jun. 2014.

SANTANA, Kátia de Cássia. Efeitos do Programa Dinheiro Direto na Escola na gestão escolar.2011. 193 f. Dissertação (Mestrado em Educação) - Universidade Federal de Viçosa, Viçosa, 2011. Disponível em: <http: /www.tede.ufv.br/tedesimplificado/tde_arquivos/48/TDE-2012-01-24T103428Z3510/Publico/texto\%20completo.pdf.>. Acesso em: 08 nov. 2014.

SANTOS, Inalda Maria dos. Política de financiamento da educação e participação da comunidade na gestão da escola. RBPAE, v. 2, n.2, p. 315-329, jul./dez. 2006. Disponível em: <http: /seer.ufrgs.br/rbpae/article/viewFile/18887/11001.>. Acesso em: 28 jun. 2014.

SHIROMA, Eneida Oto; CAMPOS, Roselane Fátima; GARCIA, Rosalba Maria Cardoso. Decifrar textos para compreender a política: subsídios teóricos-metodológicos para a análise de documentos. Perspectiva, Florianópolis, v. 23, n. 02, p. 427-446, jul./dez. 2005. Disponível em: <http//educa.fcc.org.br/scielo.php?pid=S010254732005000200009\&script=sci_arttext.>. Acesso em: 02 set. 2014.

\section{Como referenciar este artigo}

LIMA, Michelle Fernandes et al. Avanços e desafios no processo de implementação do programa nacional de alimentação escolar (PNAE) e o programa dinheiro direto na escola (PDDE). Revista on line de Política e Gestão Educacional, Araraquara, v.20, n.2, p. 301-321, 2016. Disponível em: 〈http://dx.doi.org/10.22633/rpge.v20.n2.9465>. ISSN: 1519-9029.

Submetido em: maio/2016

Aprovado em: jul/2016 